\title{
Creation Features of Devices for Testing Nasal Breathing
}

\author{
Yana Nosova \\ ORCID 0000-0003-4310-5833 \\ Department of Biomedical Engineering \\ Kharkiv National University of \\ Radio Electronics \\ Kharkiv, Ukraine \\ yana.nosova@nure.ua \\ Ibrahim Younouss Abdelhamid \\ ORCID 0000-0003-2611-2417 \\ Department of Biomedical Engineering \\ Kharkiv National University of \\ Radio Electronics \\ Kharkiv, Ukraine \\ ibrahim.younouss.abdelhamid@nure.ua
}

\author{
Maksym Tymkovych \\ ORCID 0000-0001-5613-1104 \\ Department of Biomedical Engineering \\ Kharkiv National University of \\ Radio Electronics \\ Kharkiv, Ukraine \\ oleh.avrunin@nure.ua \\ Oleg Avrunin \\ ORCID 0000-0002-6312-687X \\ Department of Biomedical Engineering \\ Kharkiv National University of \\ Radio Electronics \\ Kharkiv, Ukraine \\ maksymtymkovych@nure.ua
}

\author{
Sofia Khudaieva \\ ORCID 0000-0002-1247-5279 \\ Department of Biomedical Engineering \\ Kharkiv National University of \\ Radio Electronics \\ Kharkiv, Ukraine \\ sofia.khudaieva@nure.ua \\ Birgit Glasmacher \\ ORCID 0000-0002-2452-1666 \\ Institute for Multiphase Processes \\ Leibniz University of Hannover \\ Hannover, Germany \\ secretariat@imp.uni-hannover.de
}

\begin{abstract}
The article is devoted to the questions of metrological certification of tests of the device of rhinomanometry type PRX. The main stages of the methodology of metrological certification, as well as design and technological aspects in the development of rhinomanometers with a measuring unit are described.
\end{abstract}

Keywords-respiratory, rhinomanometry, pressure drop, nasal breathing

\section{INTRODUCTION}

In Ukraine, protecting public health is one of the most important state tasks [1, 2] aimed at organizing and increasing the production of domestic medical equipment, improving the quality of medical care, and introducing standards for the provision of medical care based on the principles of evidence-based medicine.

However, the creation of an effective system of diagnostic and therapeutic measures in Ukrainian clinics is hampered by the insufficient provision of medical facilities with modern medical equipment, since up to $70 \%$ of the medical equipment used is physically worn out, morally obsolete and needs to be replaced [2].

At the same time, the needs for medical equipment are met at the expense of domestic manufacturers by no more than $30 \%$ [2]. It follows that the use of scientific and technological potential to increase the range of domestic medical equipment products, the ability to compete in both domestic and foreign markets, is a strategic task for Ukrainian medical instrument making.

Relevance and purpose of research.

Recently, there has been a significant increase in the prevalence of upper respiratory tract diseases [3]. However, in Ukraine, in clinical practice, instrumental methods for examining the respiratory function of the upper respiratory tract and the corresponding rhinomanometry devices are rarely used. The rhinomanometry method involves measuring the pressure drop across the nasal passages and the corresponding air flow during breathing to determine the value of the aerodynamic drag coefficient [4].

Currently, there are only a few rhinomanometer models on the market of medical respiratory equipment, the main of which are ATMOS 200 and ATMOS 300 (ATMOS Medical system GMB, Germany) [4, 5] and their analogues, for example, Rinolan rhinomanometer from Mitsar (RF, St. Petersburg). All of the above rhinomanometers are based on the method of anterior active rhinomanometry, which, according to the developers, is the least uncomfortable for the patient, but has limited diagnostic capabilities.

Therefore, it is relevant to create domestic rhinomanometric equipment that allows expanding diagnostic capabilities and increasing the reliability of the measured indices of nasal breathing, as well as the development of metrological certification and verification methods for both newly created and existing devices.

Formulation of the problem.

The object of the test is an experimental model of a device developed at KHNURE for determining the differential flow rate characteristics (PRX) in low pressure air ducts, which is part of the KRM computer rhinomanometry for testing nasal breathing of the TNDA of the PRX type. A detailed description of the structural diagram and design of the PRX device is given in $[4,6]$. It consists of: a measuring unit containing pressure and air flow sensors, the signals from which are transmitted to the converter unit, in which the output signals of the sensors are digitized using an analog-to-digital converter and transferred via USB to a personal computer of the PC in which highlevel signal processing, visualization, analysis and recording of measurement results.

The justification of the diagnostic indicators of the rhinomanometry method is given in [4], therefore, further we consider only the numerical values of the parameters of the 
measured quantities and the basic medical and technical requirements:

- the maximum pressure drop in the nasal passages can reach values up to $40 \mathrm{kPa}$;

- the maximum air flow during breathing in the inspiration cycle according to spirometry is up to 81 / $\mathrm{s}$ [2];

- the measurement range of auxiliary sensors that determine the pressure drop in the submask space during inhalation and exhalation can be selected on the basis of the assumption that the aerodynamic resistance of the inlet breathing equipment (mask and connecting hoses) is not less than an order of magnitude lower than the aerodynamic resistance of the respiratory tract, which is confirmed experimentally $[4,6]$;

- when choosing analog sensors, it is necessary to take into account that the error of most standard primary transducers used in medical equipment for breathing diagnostics is about $5 \%$, and the quantization step when digitizing an analog signal should be less than $10 \%$ of the measurement error. Therefore, the quantization step should not exceed $0.5 \%$ of the maximum signal value, which corresponds to 256 levels of an 8-bit ADC;

- given that the duration of the breathing cycle can be from 0.5 to $10 \mathrm{~s}[2,4,8]$, as well as the possibility of conducting examinations in dynamic mode when studying the relatively high-frequency components (up to tens of $\mathrm{Hz}$ ) of the air flow signal in diagnosing the function of the nasal valve [8], it is necessary, accordingly with the sampling theorem, to select the sampling frequency of the measuring signals of the order of hundreds of $\mathrm{Hz}$;

- also one of the main requirements for widespread use of the device in clinical practice is the simplicity of performing preparatory procedures by medical personnel (sterilization, adjustment, calibration) and the examination itself (selection of measurement modes, data analysis and visualization).

\section{THE MAIN Stages OF THE METHOdOLOGY OF METROLOGICAL CERTIFICATION}

The tests were carried out on a measuring installation, the combined circuit of which is shown in Fig. 1. Structurally, the PRX device consists of a RA flow meter, which is installed in the VT air duct, a BPD pressure transducer block, an ADC analog-to-digital converter module, a USB interface, and a personal computer.

In the body of the flowmeter there is an internal cylindrical diffuser with an expansion of diameters towards the source of air consumption (a Ventury nozzle is used as the basis of the principle of the flowmeter operation). An adapter with a $\mathrm{KO}$ non-return valve and a pressure test point for pressure transducer is attached to the flowmeter body. A mask with an inlet channel $B$ for the passage of inhaled and exhaled air and a channel $G$ in the form of a flexible sleeve RD2, which enters the inside of the mask and serves to communicate with the patient's mouth by holding the tip of the sleeve with lips, is mounted to the outlet of the adapter (it is advisable to use a rigid plastic mouthpiece to exclude the possibility of clamping lips or teeth of a flexible sleeve).

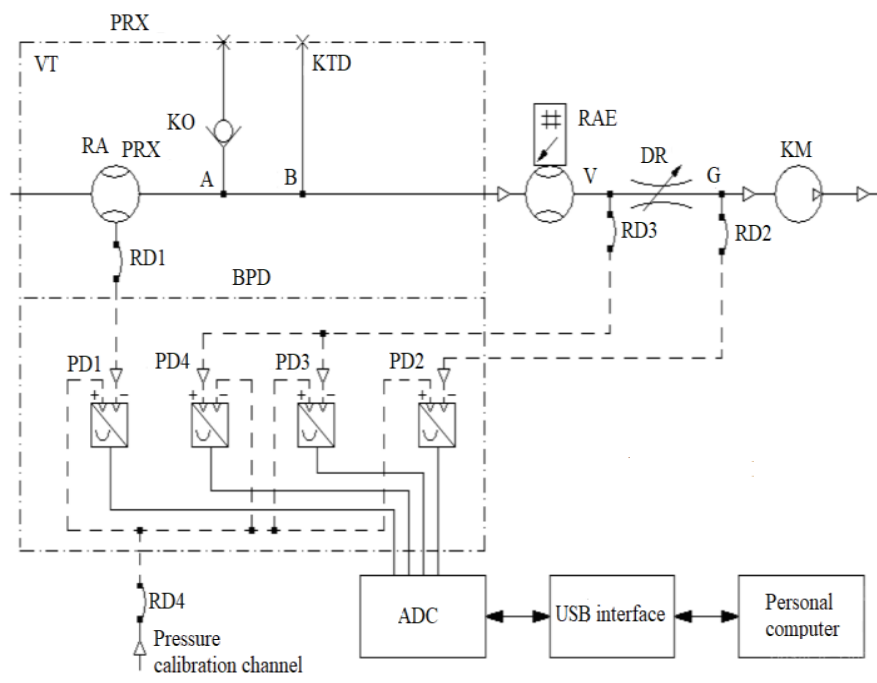

Fig. 1. Combined bench setup for metrological certification of PRX device.

The BPD unit contains pressure transducers PD1 - PD4 with electrical connectors and flexible hoses for communicating pressure transducers with a flowmeter RA (RD1) and an oral cavity G (RD2 and RD3). The flexible sleeve RD4 is used for simultaneous testing (verification) of pressure transducers PD1 - PD4. Pressure measurement is performed at the following points: PD1 - pressure (vacuum) in the flowmeter RA; PD2 - pressure (discharge) in the patient's oral cavity (at point $\mathrm{G}$ ) behind the nasal passages (chokes DR1 and DR2); PD3 - pressure (vacuum) at the entrance to the mask (channel B); PD4 - overpressure at the outlet of the mask (channel B).

The KO non-return valve, connected at point A, serves to limit the excess pressure in the exhalation cycle in order to avoid damage to the PD1 - PD4 transducers and prevents the mask from detaching from the patient's face due to the high aerodynamic resistance of the Ventury nozzle. The pressure test point $\mathrm{B}$ of the CTD is used to connect an additional pressure transmitter (if necessary).

Thus, when testing a patient, the air flow inhaled through the nose and the pressure drop at the resistances DR1 and DR2 (simultaneously on two nasal passages or alternately) are determined. Processing of the test results is carried out by constructing a graphical dependence of the differential pressure on the flow rate and calculating the ratio of the differential pressure to flow rate and air flow rate. In the reverse flow of air (expiration), only overpressure (measured by the transducer) is subject to control PD4) to indicate the phase of expiration. It should be noted that when using a non-return valve, the readings of the PD4 sensor do not exceed $100 \mathrm{~Pa}$.

The measurement setup diagram also shows: an air flow source (KM compressor), an adjustable choke DR to create resistance, and a RAE reference flowmeter with an electrical analog output signal. To create a stable airflow when purging a PRX device, a flow source with a power of about $1600 \mathrm{~W}$ is required.

The use of a calibration (reference) RAE flow meter makes it possible to assess the accuracy of the data measured by the PRX device and, if necessary, to adjust the value of 
the flow coefficient in order to minimize the error. During the tests, the standard of the Caliber unit of flow and the Artwik MC2-R pressure calibrator (ZAO Radian, RF) were used.

The PRX device performs the following functions:

- simultaneous control of pressure drop and flow in the test channel;

- processing the test results by constructing a graphical dependence of the differential pressure on the flow rate and calculating the ratio of the differential pressure to flow rate and air flow rate.

\section{DESIGN AND TECHNOLOGICAL ASPECTS IN THE DEVELOPMENT OF RHINOMANOMETERS WITH A MEASURING UNIT LIKE PRX}

The technical implementation of the KRM computer rhinomanometry provides for the selection and coordination of the hardware included in the measuring, converting and interface modules, the development of the device design, as well as the creation of the corresponding control software. The main technical requirements when choosing sensors for the TNDA PRX computer rhinomanometry are: high sensitivity, lack of hysteresis, linearity, stability, the least influence of external factors; simplicity and manufacturability of the design, the possibility of interchangeability and sanitization. Based on this, it is advisable to choose analog tensor-resistive differential sensors of Motorola Freescale Semiconductor MPX5010DP [6] as pressure sensors PD1 - PD4, designed to measure small pressure drops, including in medical applications, and having a built-in amplifier that allows connecting their conclusions, directly to the ADC signal inputs.

It is advisable to implement the converter unit on the basis of the L - Card E14-140 multichannel specialized measuring module, the main components of which are the 14-bit LTC1416 analog-to-digital converter (ADC), the AVR AtMega8515 microcontroller and the PDIUSB12D interface module for interaction with a PC via a USB port.

The functions of the last two modules can also be realized using a high-speed 32-bit ARM processor. The digitized signals from pressure and flow sensors with a sampling frequency of $500 \mathrm{~Hz}$ are transmitted via a USB interface to a PC for further processing and analysis.

The ADC quantization step is about $0.6 \mathrm{~Pa}$ for sensors with a measurement limit of $10 \mathrm{kPa}$, which is two orders of magnitude higher than the allowable limit (10\%) of the maximum error $(5 \%)$ of primary measurements converters, which for used sensors is $250 \mathrm{~Pa}$.

Considering the small load on the data transfer channel and the relatively small amount of stored information, double-byte values from four sensors (three pressure sensors and an air flow sensor) with a frequency of $500 \mathrm{~Hz}$, the data transfer speed on the interface will be about $4 \mathrm{kB} / \mathrm{s}(32 \mathrm{kB} /$ $\mathrm{s})$. Therefore, for communication with a $\mathrm{PC}$, it is advisable to use the USB-2.0 interface in the Low-speed data transfer mode with a data exchange rate range of 10 - $1500 \mathrm{Kbit} / \mathrm{s}$.

The theoretical justification for the use of a Venturi nozzle with a quadratic functional dependence of the pressure drop on the flow rate $[6,7]$ is the presence of turbulent regime of air flow in the nasal cavity, which is confirmed by the data of most studies [2 - 6].

In fig. 2 shows a semi-structural flowmeter based on a Venturi nozzle, where a hole 2 with a diameter $d$ is made in the housing 1 , in which a pressure differential is measured using a hole 3 and a pressure transducer PD1 of a differential type with an analog output.

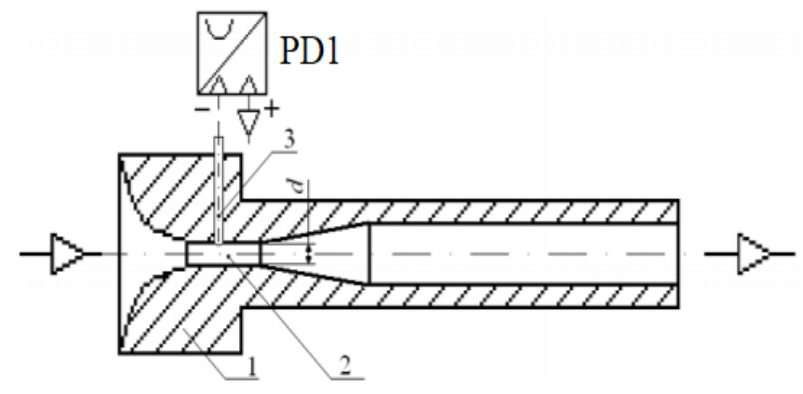

Fig. 2. Semi-constructive flowmeter based on a Ventury nozzle.

The message of the tube 3 with the input channel (receiver) "-" in the PD1 converter corresponds to the measurement of vacuum (vacuum) in the pipeline, and the + channel, measuring atmospheric pressure, allows you to obtain the pressure drop between the input channels. The technologically accurate design of the Venturi nozzle (according to GOST 10921 [7]) is advisable to implement on an automated machine with numerical control for all three sizes.

To increase the accuracy of measurements, it is advisable for patients with different physical abilities to provide Ventury nozzles with different diameters of the inlet openings ( $7 \mathrm{~mm}, 8 \mathrm{~mm}$ and $9 \mathrm{~mm})$, respectively for small (up to $4 \mathrm{hp}$ ), medium (up to $61 / \mathrm{s}$ ) and large (up to $81 / \mathrm{s}$ ) air flow during inspiration (see Fig. 3, a). Pre-calibration of PD1 ... PD4 sensors is carried out using a cup water pressure gauge (see Fig. 3, b), after exposure of the PRX-device to the room for 15 minutes.

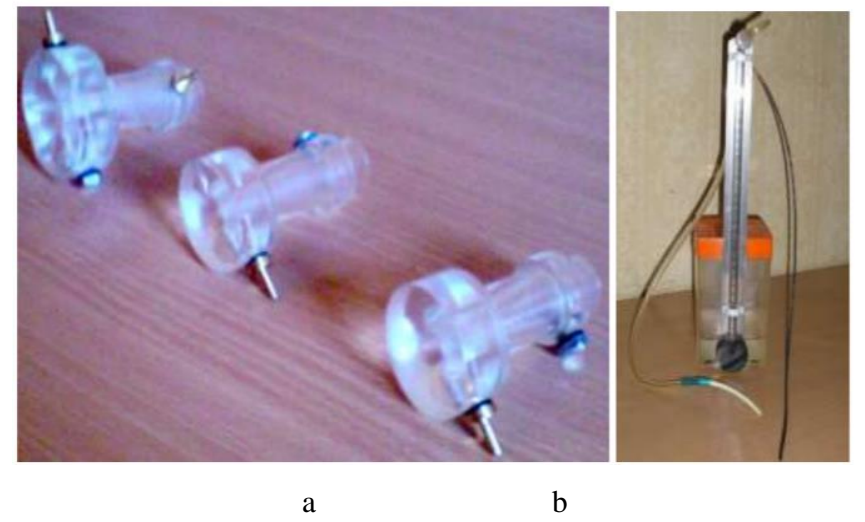

Fig. 3. Type of individual structural elements of the TNDA-PRX device:a Venturi nozzles for different diameters of the inlets, b - adjustment water manometer.

The main requirements for the software are: the ability to implement algorithms for statistical processing of data to increase the repeatability of survey results by analyzing a dynamic measurement model, conducting automated 
processing of diagnostic indicators with the possibility of flexible software changes by the developer to improve diagnostic algorithms, the simplicity of calibration procedures for sensors and monitoring of measured values, as well as protection against unauthorized access.

\section{CONCLUTION}

A methodology has been developed for metrological certification of a PRX device (determination of differential flow characteristics) as an individual measuring instrument included in the TND-PRX type computer rhinometery. According to the results of the metrological certification of the PRX device, it was found that the error in determining the measured parameters (air flow and pressure drops) is not more than $5 \%$ (certificate of state metrological certification No. 05-0102 of 01.04.2010), which allowed for preliminary clinical testing of the device and is the first step for its certification as a medical device.

To ensure flow measurement in the full range of pressure changes of the PD1 transducer and to increase the accuracy of measurements, the PRX device is equipped with RA flow meters with three nominal nozzle diameters $-7 ; 8$ and $9 \mathrm{~mm}$. In this case, the maximum values of the relative error in measuring the air flow do not exceed 4.9 in absolute value; 3.9 and $3.1 \%$ for Ventury nozzles with diameters of $7 ; 8$ and $9 \mathrm{~mm}$, respectively, and when measuring pressure, the maximum relative error in absolute value was $3.5 \%$.

The prospect of this work is to study the influence of individual characteristics of the patient's breathing on the diagnostic results and to improve the dynamic model for analyzing rhinomanometry data.

\section{ACKNOWLEDGMENT}

The exchange program with East European Countries funded by DAAD (Ostpartnerschaften, project number 54364768) and joint Ukraine-Germany project MESUBMBF 2019-2020 "3D-Model - Implementation of rapid prototyping to design and model the upper respiratory tract in normal and typical pathologies"

\section{REFERENCES}

[1] Nosova, Ya V., Kh I. Faruk, and O. G. Avrunin. "A tool for researching respiratory and olfaction disorders." Telecommunications and Radio Engineering 77.15 (2018): 1389-1395.

[2] Nosova, Y., I. Younouss Abdelhamid, and O. Gryshkov. "Using 3D printing technology to full-scale simulation of the upper respiratory tract." Informatyka, Automatyka, Pomiary W Gospodarce I Ochronie Srodowiska, Vol. 9, no. 4, Dec. 2019, pp. 60-63, doi:10.35784 / iapgos.681.

[3] Al_Omari, Ahmad Khaleed, Husham Farouk Ismail Saied, and Olig Grigorovitsh Avrunin. "Analysis of Changes of the Hydraulic
Diameter and Determination of the Air Flow Modes in the Nasal Cavity." Image Processing and Communications Challenges 3. Springer, Berlin, Heidelberg, 2011. 303-310.

[4] Fyrmpas, Georgios, et al. "The value of bilateral simultaneous nasal spirometry in the assessment of patients undergoing septoplasty." Rhinology 49.3 (2011): 297.

[5] Saied, Husham Farouk Ismail, Ahmad Khaleed Al_Omari, and Olig Grigorovitsh Avrunin. "An Attempt of the Determination of Aerodynamic Characteristics of Nasal Airways." Image Processing and Communications Challenges 3. Springer, Berlin, Heidelberg, 2011. 311-322.

[6] Zhang, G. H., et al. "Correlation between subjective assessment and objective measurement of nasal obstruction." Zhonghua er bi yan hou tou Jing wai ke za zhi= Chinese Journal of Otorhinolaryngology Head and Neck Surgery 43.7 (2008): 484-489.

[7] Tingelhoff, Kathrin, et al. "Comparison between manual and semiautomatic segmentation of nasal cavity and paranasal sinuses from CT images." 2007 29th Annual International Conference of the IEEE Engineering in Medicine and Biology Society. IEEE, 2007.

[8] Vogt, Klaus, et al. "4-Phase-Rhinomanometry (4PR)--basics and practice 2010." Rhinology. Supplement 21 (2010): 1-50.

[9] Zambetti, G., et al. "Study and application of a mathematical model for the provisional assessment of areas and nasal resistance, obtained using acoustic rhinometry and active anterior rhinomanometry." Clinical Otolaryngology \& Allied Sciences 26.4 (2001): 286-293.

[10] Zhang, Gehua, et al. "Nasal airway volume and resistance to airflow." American journal of rhinology 22.4 (2008): 371-375.

[11] Ismail, Husham Farouk, et al. "The role of paranasal sinuses in the aerodynamics of the nasal cavities." International Journal of Life Science and Medical Research 2.3 (2012): 52-55.

[12] Avrunin, Oleg G., et al. "Study of the air flow mode in the nasal cavity during a forced breath." Photonics Applications in Astronomy, Communications, Industry, and High Energy Physics Experiments 2017. Vol. 10445. International Society for Optics and Photonics, 2017.

[13] Farouk, H., and O. Avrunin. "Comparison Discriminate Characteristics Between Modern TNDA-PRH Rhinomanometer And Previously Methodology." International Journal of General Engineering and Technology (IJGET) ISSN (2013): 2278-9928.

[14] SHELTON, DIANA M., and NOEMI M. EISER. "Evaluation of active anterior and posterior rhinomanometry in normal subjects." Clinical Otolaryngology \& Allied Sciences 17.2 (1992): 178-182.

[15] Toh, Song-Tar, Cheng-Hui Lin, and Christian Guilleminault. "Usage of four-phase high-resolution rhinomanometry and measurement of nasal resistance in sleep-disordered breathing." The Laryngoscope 122.10 (2012): 2343-2349.

[16] Nosova, Yana, et al. "The use of statistical characteristics of measured signals to increasing the reliability of the rhinomanometric diagnosis." Photonics Applications in Astronomy, Communications, Industry, and High-Energy Physics Experiments 2016. Vol. 10031. International Society for Optics and Photonics, 2016.

[17] Avrunin, Oleg G., et al. "Principles of computer planning in the functional nasal surgery." Przegląd Elektrotechniczny 93.3 (2017): 140-143.

[18] Nosova, Yana, Oleg Avrunin, and Valery Semenets. "Biotechnical system for integrated olfactometry diagnostics." Innovative technologies and scientific solutions for industries 1 (1) (2017): 6468 . 